J Sci.Univ.Kelaniya 6 (2011) : 65-75

\title{
SYNTHESIS OF CHITOSAN STABILIZED SILVER NANOPARTICLES USING GAMMA RAY IRRADIATION AND CHARACTERIZATION
}

\author{
M.A. HETTIARACHCHI AND P.A.S.R. WICKRAMARACHCHI ${ }^{*}$
}

Department of Chemistry, University of Kelaniya, Sri Lanka

\begin{abstract}
Chitosan stabilized silver nanoparticles (AgNPs) were synthesized using gamma ray irradiation. Four different sample solutions were prepared $\left[1 \mathrm{mM} \mathrm{AgNO}_{3}\right.$ in $0.1 \%$ (w/v) chitosan, $1 \mathrm{mM} \mathrm{AgNO}_{3}$ in $0.5 \%$ (w/v) chitosan, $2 \mathrm{mM} \mathrm{AgNO}$ in $0.1 \%$ $(\mathrm{w} / \mathrm{v})$ chitosan $2 \mathrm{mM} \mathrm{AgNO}_{3}$ in $0.5 \%$ (w/v) chitosan] with controls maintaining dose of radiation at $20 \pm 2 \mathrm{kGy}$. The formation of AgNPs were determined by the appearance of the characteristic colour of the AgNPs, using the surface plasmon resonance band (SPR) at 400-432 $\mathrm{nm}$ range and the N-H band of the FT-IR spectrum. Stability of the maximum absorption wave lengths of the samples was monitored for three months by UV-visible spectroscopy. The particle size distribution of the stabilized sample, showed a wide distribution of 28-1106 nm. The sample, $2 \mathrm{mM}$ $\mathrm{AgNO}_{3}$ in $0.5 \%(\mathrm{w} / \mathrm{v})$ chitosan was stable for three months. FT-IR spectroscopic analysis revealed a shifting of N-H stretching vibration band from $3367-3228 \mathrm{~cm}^{-1}$ with the introduction of nanoparticles.
\end{abstract}

Keywords : Silver nanoparticles, Chitosan, Gamma ray irradiation

\section{INTRODUCTION}

The application of nano scale materials and nanocomposites containing nanoparticles is an emerging area of nanoscience and technology. Usually particles ranging from 1-100 $\mathrm{nm}$ in diameter are known as nanoparticles (Huang et al. 2004). Being in nano scale, these nanoparticles have high surface:volume ratio. Therefore they often show unique and considerably different physical, chemical and biological properties compared to their macro scaled counterparts. Silver nanoparticles (Ag NPs) have attracted much attention due to their versatile applications in many areas

\footnotetext{
* Corresponding author: Email: suranga@kln.ac.lk
} 
such as medicine (Silver et al. 2006), textiles (Lee et al. 2005, Tarimala et al. 2006), sensors and detectors (Vaseashta and Malinvoska 2005), catalysis (Choi et al. 2005), nanocomposites (Zhang et al. 2001, Wang and Chen 2006), agriculture (Park et al. 2006) and waste water treatment (Jain and Pradeep 2005).

Generally, metal nanoparticles aggregate among themselves and progressively grow into larger clusters and eventually precipitates, deviating from nanoscale. This avoids the effectiveness of synthesized nanoparticles and discourages its application. Coalescence may be prevented by adding a cluster stabilizer. Synthetic polymers such as polyvinyl chloride (PVC) (Savage et al. 2009), polyvinyl alcohol (PVA) (Filippo et al. 2009) and polyvinyl pyrrolidone (PVP) (Du et al. 2007, Yoksan and Chirachanchi 2009) are already in usage as stabilizing polymers of $\mathrm{Ag}$ NPs. Due to non-biodegradability and toxicity of synthetic polymers, at present a considerable attention has been drawn on the use of natural polymers to stabilize the AgNPs. Furthermore, especially in medical applications, additional steps are necessary to remove the synthetic polymer after synthesis, which makes the synthesis process much complex and less economic. Once the stabilizer is eliminated there is a tendency to diminish the stability of synthesized AgNPs, altering the effective particle size. Therefore, natural polysaccharides being an environment benign, biodegradable, highly abundant and low cost, they are more favorable to be utilized as a stabilizer for synthesized AgNPs.

Chitosan, the deacetylated product of chitin, is a natural polysaccharide with a great potential to be a substitute for synthetic stabilizers. Chitosan consists of glucosamine and $N$-acetyl glucosamine units linked together by $\beta$-1,4-glucosidic bonds. Chitosan shows unique polycationic, chelating and film forming properties as it is an oxygen rich linear polysaccharide having active amino and hydroxyl groups (Wei et al. 2009). Therefore, chitosan exhibits a number of interesting biological activities such as biocompatibility, biodegradability, non-toxicity, non-antigenicity and adsorption properties.

In the synthesis of AgNPs, generally $\mathrm{AgNO}_{3}$ is used as the salt precursor. Reduction of $\operatorname{Ag}(\mathrm{I})$ to $\operatorname{Ag}(\mathrm{o})$ can be achieved by chemical, electrochemical and photochemical reduction as well as thermal, ultrasound (Ye et al. 2007), microwave (Jiang et al. 2006), gamma and electron irradiation (Du et al. 2007). Although, chemical methods of synthesizing AgNPs are simpler than physical methods, they have several disadvantages over physical methods. Chemical reduction leaves the residual reducing agents and hence the final product needs further purified. Furthermore, chemical methods may associate with environmental toxicity and 
biological hazards. Therefore, a development of a green method to synthesize AgNPs is desired. A method using gamma radiation provides more convenient and a cleaner approach.

Gamma radiolysis of aqueous solution yields several products including hydrated electrons $\left(\mathrm{e}_{\mathrm{aq}}^{-}\right)$and hydrogen atoms $\left(\mathrm{H}^{*}\right)$ having the powerful reducing ability. These hydrated electrons reduce $\operatorname{Ag}(\mathrm{I})$ into $\operatorname{Ag}(\mathrm{o})$ (Eq.1). The neutral atom $\left(\mathrm{Ag}^{\circ}\right)$ reacts with $\mathrm{Ag}^{+}$to form the relatively stabilized Ag clusters as shown in Eq.(2) and (3) (Yoksan and Chirachanchai 2009).

$$
\begin{aligned}
& \mathrm{Ag}^{+}+\mathrm{e}_{\mathrm{aq}}^{-} \rightarrow \mathrm{Ag}^{\mathrm{o}} \\
& \mathrm{Ag}^{\mathrm{o}}+\mathrm{Ag}^{+} \rightarrow \mathrm{Ag}_{2}{ }^{+} \\
& \mathrm{Ag}_{2}{ }^{+}+\mathrm{Ag}^{+} \rightarrow \mathrm{Ag}_{3}{ }^{2+}
\end{aligned}
$$

The morphology (particle size and shape) and the stability of the resulting Ag NPs are highly dependent on the concentration of $\mathrm{AgNO}_{3}$, concentration of the polymer and the method and/or reagents used for reduction.

A thorough literature analysis revealed only a few studies using chitosan (stabilizer) and gamma irradiation (method of reduction) in the synthesis of AgNPs (Wei et al. 2009, Yoksan and Chirachanchai 2009). Therefore, this study aims at exploring the possibility of synthesizing AgNPs using a $\gamma$-irradiation (chemical free reduction method) and chitosan (a biodegradable, biocompatible natural polymer) as the stabilizer under normal atmospheric conditions.

\section{MATERIALS AND METHODS}

\section{Synthesis of silver nanoparticles}

Industrial grade chitosan was purchased from the Nuclear Research Institute, Vietnam (degree of deacetylation is $79 \%$ ). Chitosan solutions $\{(0.1 \%(\mathrm{w} / \mathrm{v})$ and $0.5 \%$ $(\mathrm{w} / \mathrm{v})\}$ were prepared by dissolving chitosan in $1 \%$ acetic acid (Molecular weight: $60.05 \mathrm{~g} / \mathrm{mol}$, assay: 99\%, Merck Ltd, India). Due to the poor solubility of chitosan, the mixtures were kept overnight until a clear solution was obtained. The solutions were filtered through Whatman No.3 filter papers to eliminate traces of insoluble fractions. A fresh stock solution of $\mathrm{AgNO}_{3}$ (Molecular weight: $169.87 \mathrm{~g} / \mathrm{mol}$, assay: 99\%: Techno pharmchem, Bahadurgarh, India) was prepared by dissolving solid $\mathrm{AgNO}_{3}$ in $1 \%(\mathrm{v} / \mathrm{v})$ acetic acid solution. Six samples were prepared as indicated in Table 1 each having two replicates. 
Table 1: Concentrations of the prepared samples

\begin{tabular}{|c|c|}
\hline $\mathrm{AgNO}_{3}$ concentration & $\begin{array}{c}\text { Chitosan concentration in 1\% acetic } \\
\text { acid solution(v/v) }\end{array}$ \\
\hline Sample solutions & $0.1 \%(\mathrm{w} / \mathrm{v})$ \\
\hline $1 \mathrm{mM}$ & $0.5 \%(\mathrm{w} / \mathrm{v})$ \\
\hline $1 \mathrm{mM}$ & $0.1 \%(\mathrm{w} / \mathrm{v})$ \\
\hline $2 \mathrm{mM}$ & $0.5 \%(\mathrm{w} / \mathrm{v})$ \\
\hline $2 \mathrm{mM}$ & \\
\hline Controls & 0 \\
\hline $1 \mathrm{mM}$ & 0 \\
\hline $2 \mathrm{mM}$ & \\
\hline &
\end{tabular}

The prepared samples were stirred at room temperature $\left(29 \pm 1^{\circ} \mathrm{C}\right)$ for about 15 min for homogeneous mixing. The samples were irradiated at $1.5 \mathrm{kGy} / \mathrm{hr}$ to a total dose of 20 $\pm 2 \mathrm{kGy}$ using JS8900 Co-60 panoramic-wet storage gamma ray irradiator at Ansell Lanka (Pvt) Ltd, Biyagama.

\section{Determination of the formation of silver nanoparticles}

\section{Colour}

The colour of each sample after irradiation was checked with naked eye to examine the formation of AgNPs.

\section{UV-visible spectroscopic data}

Each sample was analyzed by UV-visible spectrophotometer (Optima 3200, Tokyo, Japan) in the range 200-750 $\mathrm{nm}$ and the wavelength corresponding to maximum absorption $\left(\lambda_{\max }\right)$ was recorded. $0.1 \%(\mathrm{w} / \mathrm{v})$ and $0.5 \%(\mathrm{w} / \mathrm{v})$ chitosan in $1 \%(\mathrm{v} / \mathrm{v})$ acetic acid solutions irradiated at the same dose $(20 \pm 2 \mathrm{kGy})$ were used as blank samples.

\section{Determination of the stability of synthesized silver nanoparticles}

The inspection of the $\lambda_{\max }$ value was carried out for three months and any deviation in $\lambda_{\max }$ value was recorded.

\section{Chracterisation of silver nano - chitosan composites}

\section{Size of synthesized silver nanoparticles}

The size distribution of AgNPs was measured by the particle size analyzer (Marlven Zetasizer Nano ZS, Sri Lanka Institute of Nano Technology (Pvt) Ltd, Biyagama). 
The sample with a constant $\lambda_{\max }$ value over two months was used for this measurement.

\section{FT-IR spectroscopic data}

The sample that had a constant $\lambda_{\max }$ value over two months was subjected to FT-IR measurements. The FT-IR spectrum was recorded in the frequency range of 4000-400 $\mathrm{cm}^{-1}$ (Thermo Nicolet AVATAR 320 with a DTGS detector, University of Sri Jayawardhanapura). The spectral resolution is $4 \mathrm{~cm}^{-1}$ and $100 \mathrm{scans}$ each were used for sample and the background spectra. The instrument was purged with $\mathrm{N}_{2}$ gas. All the samples used in this analysis were in their native liquid form during the analysis.

\section{RESULTS AND DISCUSSION}

\section{Determination of the formation of silver nanoparticles}

\section{Colour}

Samples (c) to (f) showed a reddish brown to yellow colouration when observed after $24 \mathrm{hrs}$ of irradiation, showing evidence for the formation AgNPs (Table 2).

Table 2: Physical appearance of each sample recorded after 24 hrs of irradiation.

\begin{tabular}{|c|c|}
\hline Sample & $\begin{array}{l}\text { Physical appearance } \\
\text { recorded after } 24 \text { hrs of irradiation }\end{array}$ \\
\hline $\begin{array}{l}\text { Controls } \\
\text { (a) } 1 \mathrm{mM} \mathrm{AgNO} \text { in } 1 \%(\mathrm{v} / \mathrm{v}) \text { acetic acid }\end{array}$ & $\begin{array}{l}\text { Colourless; fine sediment at the } \\
\text { bottom }\end{array}$ \\
\hline (b) $2 \mathrm{mM} \mathrm{AgNO} 3$ in $1 \%(\mathrm{v} / \mathrm{v})$ acetic acid & $\begin{array}{l}\text { Colourless; fine sediment at the } \\
\text { bottom }\end{array}$ \\
\hline $\begin{array}{l}\text { Samples } \\
\text { (c) } 1 \mathrm{mM} \mathrm{AgNO}_{3} \text { in } 0.1 \%(\mathrm{w} / \mathrm{v}) \text { chitosan } \\
\text { in } 1 \%(\mathrm{v} / \mathrm{v}) \text { acetic acid }\end{array}$ & Reddish-brown solution \\
\hline $\begin{array}{l}\text { (d) } 1 \mathrm{mM} \mathrm{AgNO}_{3} \text { in } 0.5 \%(\mathrm{w} / \mathrm{v}) \text { chitosan } \\
\text { in } 1 \%(\mathrm{v} / \mathrm{v}) \text { acetic acid }\end{array}$ & Bright yellow solution \\
\hline $\begin{array}{l}\text { (e) } 2 \mathrm{mM} \mathrm{AgNO}_{3} \text { in } 0.1 \%(\mathrm{w} / \mathrm{v}) \text { chitosan } \\
\text { in } 1 \%(\mathrm{v} / \mathrm{v}) \text { acetic acid }\end{array}$ & Reddish-brown solution \\
\hline $\begin{array}{l}\text { (f) } 2 \mathrm{mM} \mathrm{AgNO}_{3} \text { in } 0.5 \%(\mathrm{w} / \mathrm{v}) \text { chitosan } \\
\text { in } 1 \%(\mathrm{v} / \mathrm{v}) \text { acetic acid }\end{array}$ & Bright yellow-orange solution \\
\hline
\end{tabular}


Controls (a) and (b) which did not contain the chitosan stabilizer showed no colour formation. This can be due to non-formation of AgNPs or instability of the synthesized AgNPs due to the absence of a stabilizer. This confirms the fact that the stabilizer plays a vital role in the synthesis of AgNPs. Also it is significant that higher the concentrations of $\mathrm{AgNO}_{3}$ and chitosan, higher the colour after irradiation.

\section{UV-visible spectroscopic data}

Surface plasmon resonance (SPR) band at 400-432 $\mathrm{nm}$ in the UV-visible spectrum indicates the formation of AgNPs (Grijalva et al. 2005). Samples (d) to (f) gave the characteristic SPR band at $420 \mathrm{~nm}$ indicating the formation of AgNPs (Figure 1).

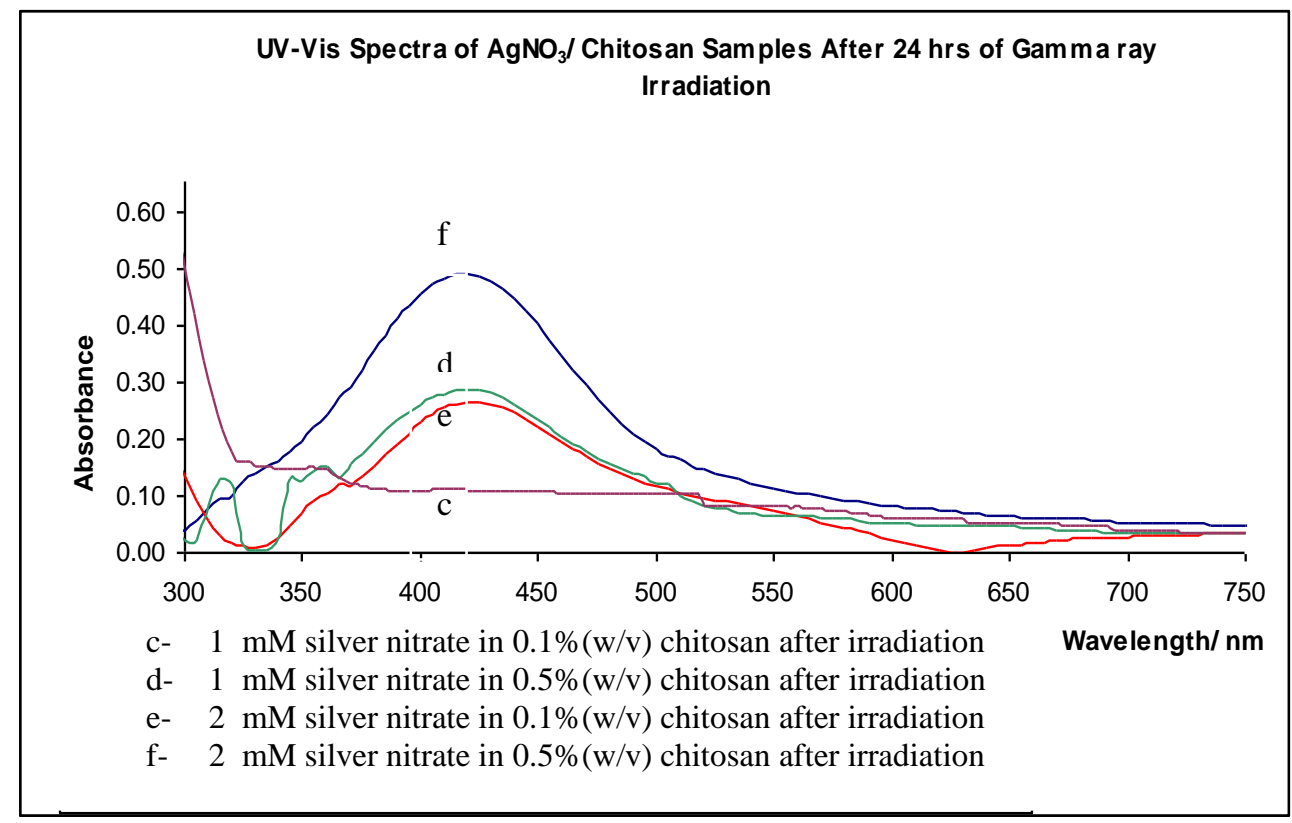

Figure 1: UV-visible spectra of $\mathrm{AgNO}_{3}$ in chitosan samples recorded after $24 \mathrm{hrs}$ of gamma ray irradiation.

Generally the shape of the SPR band is broad because the nanoparticles lay in close proximity in their size, thus the gap between conductance and non-conductance bands of nanoparticles changes slightly. Therefore, each set of particles having the same size, has its corresponding excitation due to both UV and visible radiation thus broadening SPR band.

\section{Stability of synthesized silver nanoparticles}

Only samples (d) to (f) were used for stability measurements. The sample with $2 \mathrm{mM} \mathrm{AgNO}_{3}$ in $0.1 \%$ (w/v) chitosan and $1 \mathrm{mM} \mathrm{AgNO}_{3}$ in $0.5 \%$ (w/v) chitosan show a variation in $\lambda_{\max }$ value with time $\{$ Figure 2(a)\}. Only the sample with $2 \mathrm{mM}$ $\mathrm{AgNO}_{3}$ in $0.5 \%(\mathrm{w} / \mathrm{v})$ chitosan shows constant $\lambda_{\max }$ value throughout the duration of 
the analysis $\left\{\right.$ Figure 2(b)\}. The red shift of the $\lambda_{\max }$ of the other two samples \{Figure 2(b) $\}$ indicates an increase in particle size or formation of the AgNPs aggregates. Again $0.5 \%(\mathrm{w} / \mathrm{v})$ chitosan is more efficient than $0.1 \%(\mathrm{w} / \mathrm{v})$ chitosan as a stabilizer, but the relationship between concentrations of $\mathrm{AgNO}_{3}$ and chitosan to maintain the stability of the composite remains unclear.
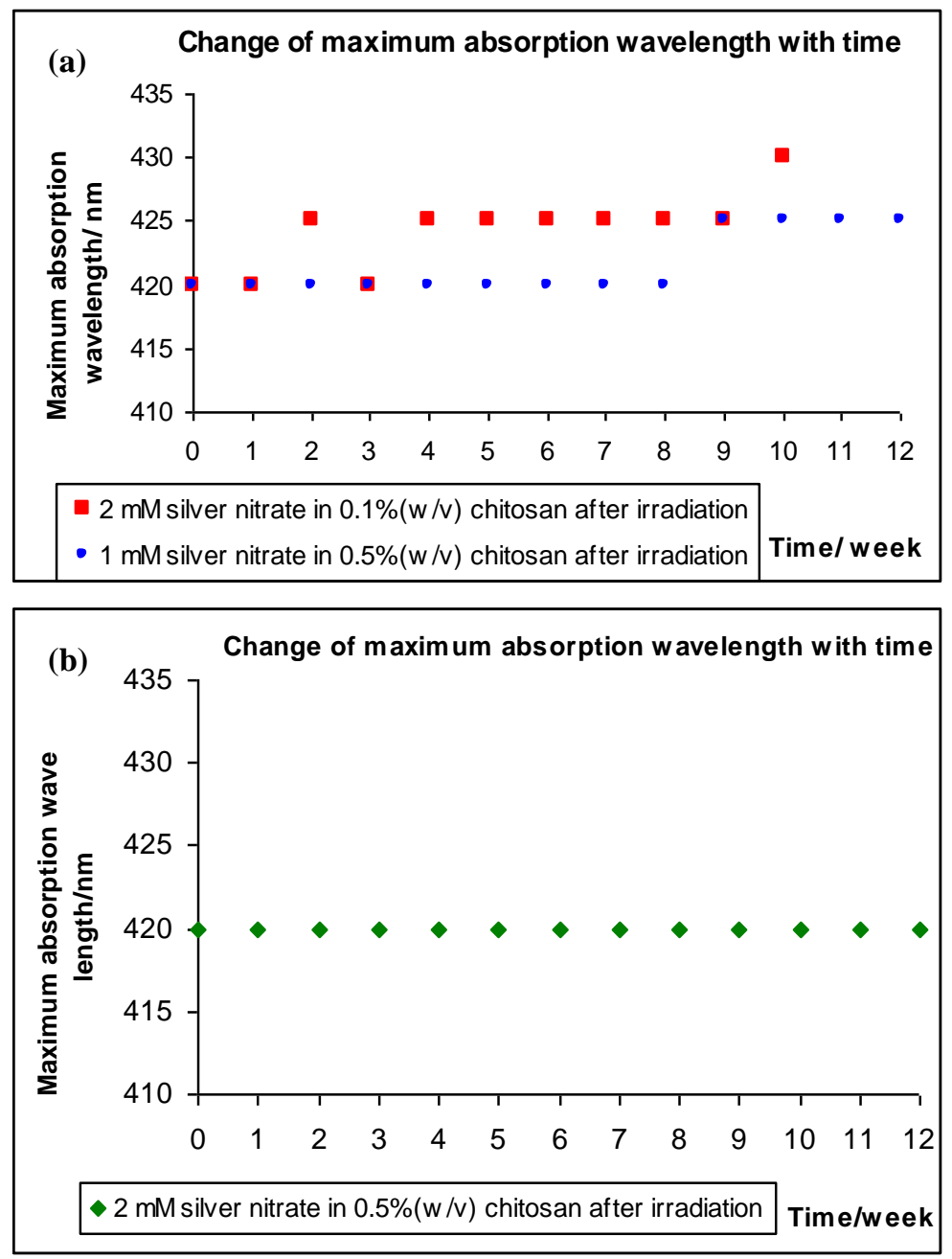

Figure 2: Variation of maximum wave length $\left(\lambda_{\max }\right)$ with time;

(a) $1 \mathrm{mM} \mathrm{AgNO} / 0.5 \%(\mathrm{w} / \mathrm{v})$ chitosan and $2 \mathrm{mM} \mathrm{AgNO} / 0.1 \%(\mathrm{w} / \mathrm{v})$ chitosan (b) $2 \mathrm{mM} \mathrm{AgNO} / 0.5 \%(w / v)$ chitosan

A good synthesis of AgNPs was achieved in $2 \mathrm{mM} \mathrm{AgNO}_{3}$ in $0.5 \%(\mathrm{w} / \mathrm{v})$ chitosan solution. It showed no deviation of the SPR band during this time period and hence it is stable for about three months. High chitosan concentrations promote 
the longer stability than lower concentrations. When $\mathrm{AgNO}_{3}$ is mixed with chitosan before irradiation, $\mathrm{Ag}^{+}$interacts with the electron abundant oxygen atoms of hydroxyl groups of the polysaccharide (Yoksan and Chirachanchi 2009).

When there are a large number of polymer chains the number of functional groups and sites for $\mathrm{Ag}^{+}$interaction increase. Then, there are more binding sites on the polymer as nucleation sites for the resulting $\operatorname{Ag}(\mathrm{o})$ atoms to aggregate during the reduction of $\operatorname{Ag}(\mathrm{I})$. Therefore, high polymer concentration promotes more binding sites. Also, high concentration of polymer acts as a physical barrier to avoid uncontrolled aggregation of AgNPs as there are more chains to envelope the surface of AgNPs. It has also been reported that higher the concentration of the stabilizer added to the system, smaller is the size of the silver colloids (Chou and Lai 2004). The sample with $2 \mathrm{mM} \mathrm{AgNO}_{3}$ in $0.1 \%$ (w/v) did not show the SPR band in the UVvisible spectrum (Figure 1). It could be attributed to the aggregation of AgNPs deviating from the nano range due to the less protection provided by low concentration of polymer chains.

\section{FT-IR spectroscopic analysis}

Although there is a possibility of overlapping $\mathrm{N}-\mathrm{H}$ and $\mathrm{O}-\mathrm{H}$ stretching vibrations, the strong band at $3300-3500 \mathrm{~cm}^{-1}$ \{Figure $3(\mathrm{a})$ \} is characteristics of $\mathrm{N}-\mathrm{H}$ stretching vibration (Wei et al. 2009). It was observed that the $\mathrm{N}-\mathrm{H}$ stretching band at $3367 \mathrm{~cm}^{-1}$ \{Figure $\left.3(\mathrm{a})\right\}$ was shifted to $3228 \mathrm{~cm}^{-1}$ \{Figure $\left.3(\mathrm{~b})\right\}$.

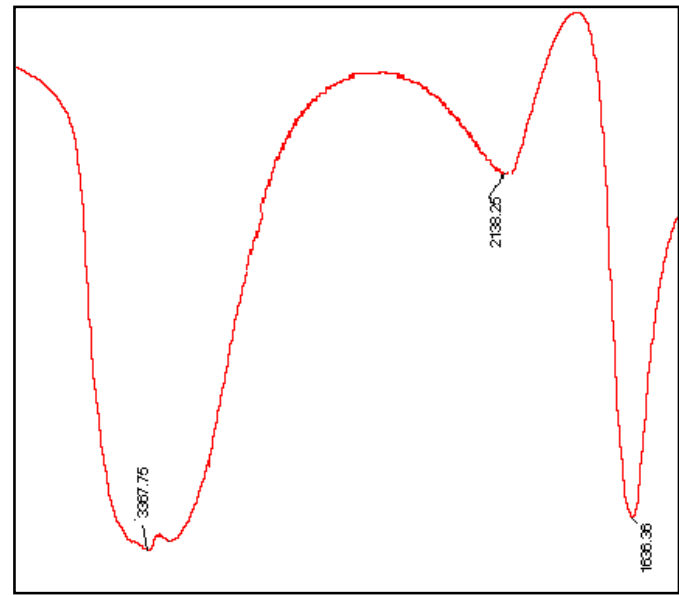

(a)

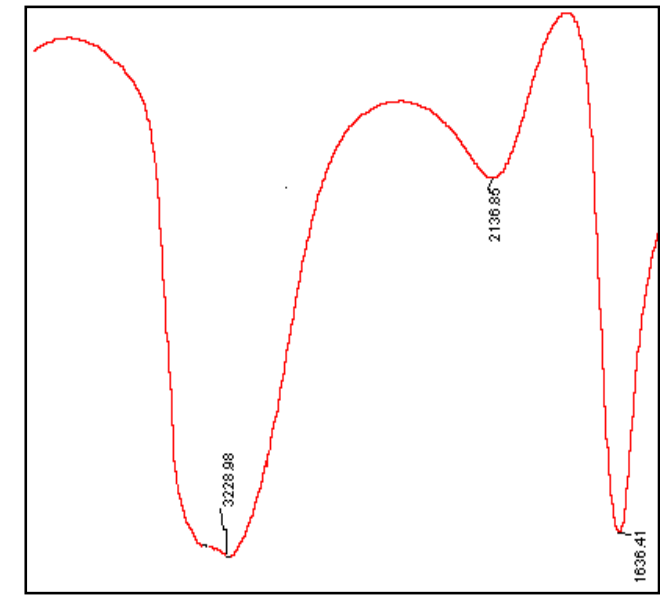

(b)

Figure 3: Comparison of FT-IR spectra for (a) $20 \pm 2 \mathrm{kGy}$ irradiated $0.5 \%$ (w/v) chitosan (b) $0.5 \%(\mathrm{w} / \mathrm{v})$ chitosan based silver nano sample synthesized by $20 \pm 2 \mathrm{kGy} \gamma$ - ray irradiation. 
This suggests that the formation of AgNPs was promoted by N-H bond (Wei et al. 2009). Authors believe that the electrostatic interaction of AgNPs to the N-H bond reduces the electron density which is distributed between $\mathrm{N}$ and $\mathrm{H}$, decreasing the $\mathrm{N}-\mathrm{H}$ bond strength. Therefore, the bond will now resonate at a lower frequency.

\section{Particle size distribution}

Particle size showed a wide distribution. The size ranges from $28-1106 \mathrm{~nm}$ in diameter, but only the particles ranging from 1-100 $\mathrm{nm}$ in diameter are considered as nanoparticles (Huang et al. 2004). Therefore, this sample contains particles which are in the nanorange as well as particles that fall outside the nanorange.

\section{CONCLUSION}

The particle size plays an important role in the applications of AgNPs as their efficiency depends on its size. Wide particle size distribution (28-1106 nm) of Ag NPs synthesized here suggests that the three parameters: concentration of $\mathrm{AgNO}_{3}$, polymer concentration and the irradiation dose which are responsible for the morphology, stability and particle size distribution should be optimized. Even though $0.5 \%(\mathrm{w} / \mathrm{v})$ chitosan is effective in stabilizing the synthesized particles for three months, the number of polymer molecules in this concentration has not been sufficient to act as a physical barrier to limit the growth of Ag nano clusters outside the nano range. Therefore, this preliminary study suggests that a higher stabilizer concentration is favorable. This method has a great potential to be developed as a green method of synthesizing AgNPs.

\section{REFERENCES}

Choi,S.H., Y.P. Zhang, A. Gopalan, K.P. Lee \& H.D Kang. 2005. Preparation of catalytically efficient precious metallic colloids by $\gamma$-irradiation and characterization. Colloids Surface A:Physiochemical and Engineering Aspects 256: 165-170.

Chou, K. \& Y. Lai. 2004. Effect of polyvinyl pyrrolidone molecular weights on the formation of nanosized silver colloids. Materials Chemistry and Physics 83: 83-88.

Du, B.D., D.V. Phu, N.N. Duy, N.T.K.L. Lan \& V.T.K.L. Lang. 2008. Preparation of colloidal silver nanoparticles in Poly(vinyl pyrrolidone) by $\gamma$-ray irradiation. Journal of Experimental Nanoscience 3 (3): 207-213. 
Filippo,E., D. Manno \& A. Serra. 2009. Poly(vinyl alcohol) capped silver nanoparticles as localized surface plasmon resonance-based hydrogen peroxide sensor. Sensors and Actuators B 138: 625-630.

Grijalva, A.S., R.H. Urbina, J.F.R. Silva, M.A. Borja, F.F. Barraza \& A.P. Amarillas. 2005. Assessment of growth of silver nanoparticles synthesized from an ethylene glycol-silver nitrate-polyvinyl pyrrolidine solution. Physica E 25: 439.

Huang, H., Q. Yuan \& X. Yang. 2004. Preparation and characterization of metalchitosan composites. Colloids and Surfaces B: Biointerfaces Vol.39. PP.31.

Jain, P. \& T. Pradeep. 2005. Potential of silver nanoparticles-coated polyurethane foam as an antibacterial water filter. Biotechnology and Bioengineering 90(1): 59-63.

Jiang, H., K.S. Moon, Z. Zhang, S. Pothukuchi \& C.P. Wong. 2006. Variable frequency microwave synthesis of silver nanoparticles. Journal of Nanoparticle Research 8: 117-124.

Lee, H.J \& S.H. Jeong. 2005. Bacteriostasis and skin innoxiousness of nanosize silver colloids on textile fabrics. Textile Research Journal 75(7): 551-556.

Park, H.P., S.H. Kim, H.J. Kim \& S.H. Choi. 2006. A new composition of nanosized silica-silver for control of various plant diseases. Plant Pathology Journal 22(3): 295-302.

Savage et al. (2009). Nanotechnology applications for clean water. William Andrew Inc.281: 281-282.

Silver, S., L.T. Phung \& G. Silver. 2006. Silver as biocides in burn and wound dressings and bacterial resistance to silver compounds. Journal of Industrial Microbiology and Biotecnology 33: 627-634.

Tarimala,S., N. Kothari, N. Abidi, E. Hequet, J. Fralick \& L. L. Dai. 2006. New approach to antibacterial treatment of cotton fabric with silver nanoparticles-doped silica using sol-gel process. Journal of Applied Polymer Science 101: 2938-2943.

Vaseashta, A. \& D. D Malinvoska. 2005. Nanostructured and nanoscale devices, sensors and detectors. Science and Technology of Advanced Materials 6: 312-318.

Wang, L. \& D. Chen. 2006. A one-pot approach to the preparation of silver-PMMA 'shell core' nanoparticle composite. Colloid Polymer Science 248: 499-454. 
Wei, D., W. Sun,W. Qian, Y. Ye \& X. Ma. 2009. The synthesis of chitosan based silver nanoparticles and their antibacterial activity. Carbohydrate Research 344: 2378

Ye, X., Y. Zhou, J. Chen \& Y. Sun. 2007. Deposition of silver nanoparticles on silica spheres via ultra sound irradiation. Applied Surface Science 253: 6264-6267.

Yoksan, R. \& S. Chirachanchai. 2009. Silver nanoparticles dispersing in chitosan solutions: Preparation by $\gamma$-ray irradiation and their antimicrobial activity. Material Chemistry and Physics 115: 296.

Zhang, Z., L. Zhang, S. Wang, W. Chen \& Y. Lei. 2001. A convenient route to polyacrylonitrile/silver nanoparticle composite. Polymer 42: 8315-8318. 